unusual in nature, or when tachycardia makes auscultation difficult. Particular examples of the value of phonocardiography in clinical medicine are best described under the individual sounds and murmurs. The normal phonocardiogram is illustrated in Fig. 2 for comparison with the later illustrations.

First Heart Sound.-When there is a loud systolic or diastolic murmur the first heart sound may not be distinguishable on auscultation, but the phonocardiograph will show that the vibrations of the first sound are slightly different from those of the murmur (Fig. 8). Occasionally the phonocardiograph shows that the first heart sound is absent and that a sound in early systole was mistaken on auscultation for the first sound. Sometimes a presystolic murmur is diagnosed on auscultation when the phonocardiogram shows a crescendic first heart sound. This mistake would not occur if the diagnosis of mitral stenosis were made only when a mid-diastolic murmur is heard. In mitral stenosis the first sound is delayed and the degree of delay as measured from the phonocardiogram may in future indicate the severity of the mitral stenosis.

Second Heart Sound.-The physiological splitting of the second heart sound due to asynchronous closure of the pulmonary and aortic valves is well shown on the phonocardiogram. The aortic component can be identified because it is better conducted to the apex. When the second component of the second sound is of low intensity it may be inaudible because of the fatiguing effect on the human hearing mechanism of the loud first component. The lack of fatiguing effect in the phonocardiograph reveals the extra sound. It is largely due to phonocardiography that the "opening snap" of the mitral valve is now diagnosed rather than "splitting of the second sound in mitral stenosis." The claquement d'ouverture had been described long ago by Potain, but has only recently been widely accepted. The phonocardiograph shows a series of high-frequency vibrations at the onset of the "R.I." wave of the apex cardiogram (Fig. 1) and often shows this sound when it is inaudible on auscultation (Fig. 7), which is valuable evidence of the presence of mitral stenosis.

Third Heart Sound.-It is difficult to differentiate on auscultation between a long third heart sound and a short diastolic murmur. The phonocardiogram enables the duration of the vibrations to be measured, and should they last more than 0.16 second they constitute a diastolic murmur. Over the age of 30 a third sound is of serious significance unless it occurs only with tachycardia, when it may be due to "summation gallop." When the nature of gallop rhythm is uncertain the phonocardiograph will clarify the problem.

Systolic Murmurs. - The phonocardiogram is very useful in distinguishing the ejection murmurs of pulmonary and aortic stenosis from the murmurs of mitral or tricuspid regurgitation or ventricular septal defect. The ejection murmurs are diamond-shaped and that of aortic stenosis ends before the second heart sound (Fig. 5). The murmur of pulmonary stenosis reaches the aortic component of the second sound but ends before the delayed pulmonary component (Fig. 6). The murmurs of mitral and tricuspid regurgitation and ventricular septal defect fill the whole of systole (Figs. 7 and 8). The tricuspid murmurs are of more variable intensity than the others, and often show a marked change during respiration.

Diastolic Murmurs.-When the murmur of aortic or pulmonary regurgitation is audible at the apex it may be difficult to decide whether there is also a mitral diastolic murmur or an Austin Flint murmur. The phonocardiogram of the aortic or pulmonary diastolic murmurs has a characteristic crescendo and decrescendo pattern (Fig. 10). This can be distinguished from the pattern of the diastolic murmur of mitral stenosis, which does not start until after the opening of the $\mathrm{A}-\mathrm{V}$ valves and is composed of coarser and more irregular vibrations (Fig. 9). The late first sound and "opening snap" of the mitral valve also confirms that mitral stenosis is present.
Continuous Murmurs.-The phonocardiogram of the murmur of persistent ductus arteriosus shows that the intensity of the vibrations is maximal at the time of the second heart sound and minimal at the beginning of ventricular systole (Fig. 11). When the to-and-fro murmurs of pulmonary or aortic valve disease coexist the phonocardiogram often helps to identify the separate murmurs. Other continuous murmurs due to such conditions as arteriovenous aneurysms or rupture of a sinus of Valsalva into the right ventricle may show features which are most easily identified by the phonocardiogram (Fig. 12).

\section{The Future of Phonocardiography}

The phonocardiograph has helped to build our present knowledge of the heart sounds and murmurs and will continue to add to this knowledge. In this respect it is like the electrocardiograph, which has taught us much of what we know about the heart and yet is of relatively little value now that this knowledge has been obtained. The use of phonocardiography is certain to increase in several ways. It will be used more and more for teaching, especially in conjunction with the tape recorder. The phonocardiogram during Müller and Valsalva manœuvres and in other physiological experiments will gradually replace the tracings taken at rest as a means of identifying unusual murmurs. Finally, the phonocardiogram itself will be used more and more as a reference tracing in order to time other graphic investigations of cardiac activity.

\section{REFERENCES}

Orías, O., and Braun-Menendez, E. (1939). The Heart Sounds and Normal and Pauhological Conditions. Oxford Univ Press, London. Rappaport, M. B., and Sprague, H. B. (1941). Amer. Heart J., 21, 257.

\section{MISSILE WOUNDS IN MALAYA}

BY

A. J. CLYNE, M.B., F.R.C.S.

Colonel, A.M.S. ; Consulting Surgeon, Far East Land Forces

This report covers the three-year period from January 1 , 1950, to December 31, 1952. The "emergency" in Malaya began in July, 1948, and from then until the end of 1949 there were 197 missile casualties sustained on operations and treated in military hospitals, with 14 deaths from wounds, including deaths before arrival at hospital. Unfortunately, records permitting detailed analysis of missile wounds during this period are not available in FARELF. On assuming responsibility for surgery in the Far East Land Forces in July, 1950, I introduced a system of reporting all missile wounds in synoptic form, which has enable an analysis to be made of wounds received from the beginning of 1950 , the treatment given, and the progress made. 'The scale and tempo of the campaign in Malaya made this possible. Also the circumstances were probably unique in modern military surgery; for casualties were admitted direct to military hospitals, where they were treated by the same surgeon until convalescent or repatriated. This has been of the greatest value.

I spent the first half of 1950 as surgeon at the military hospital at Kuala Lumpur, where casualties were admitted direct from the jungle. Subsequently I saw most of the seriously wounded cases, either during routine visits to hospitals or when they were evacuated to Singapore, where such cases normally come under my personal care.

\section{Nature of the Malayan Operations}

The anti-terrorist operations in the Federation of Malaya have followed the usual pattern of this type 
of warfare, but have been made especially difficult by the densely wooded nature of the terrain. There is nothing of the nature of a front. The enemy, merging at will with the general population, who feed them, strike irregularly at widely scattered points which cannot be anticipated. Ambushes of patrols sent out to investigate an "incident " on a rubber estate, ambushes of vehicles on roads and tracks, firing at railway coaches from the jungle - these are the typical methods of attack, and, with conditions so suited for surprise, the only really remarkable feature of the Malayan operations has been the surprisingly low number of casualties inflicted on our troops. Added to those from enemy action are the inevitable accidental wounds which occur when a large number of men of varying intelligence are constantly in possession of highly lethal weapons, usually loaded.

The surgical problem has been to manage, with limited resources, missile wounds and other injuries occurring unexpectedly at widely separated points over the whole of Malaya, often singly and never in large numbers (incidents in which there were more than 12 casualties were exceptional). Some occurred far out in the jungle, others close to a hospital, others again on a train in the middle of the night. As a result the time taken for a wounded man to reach a hospital, where he first received adequate surgical treatment, has varied from less than an hour to 96 hours. The average delay between wounding and surgical operation has been between 10 and 12 hours.

\section{Surgical Dispositions}

With no possibility of providing close surgical support for widely scattered forces, the surgical plan has been to provide centres at strategically placed military hospitals, to which casualties were brought by whatever means were available-road, rail, air, or river. These hospitals are at Taiping, covering North Malaya, at Kuala Lumpur, covering Central Malaya, and at Kluang, covering South Malaya. Casualties from South Johore went direct to Singapore. Limited emergency facilities were also provided in Pahang, where a field surgical team was located, and at the Cameron Highlands.

Use has also been made of the civil hospitals in Malaya, and we have been greatly indebted to the Malayan Medical Service for ready co-operation and assistance. Most towns of any size have a hospital, but in only a few large towns are full surgical facilities available, and, whenever possible, casualties were transferred to military hospitals either direct or after emergency treatment. The main surgical cover was at Singapore, where, at the large modern wellequipped military hospital, specialized facilities existed for orthopaedics, maxillo-facial surgery, otolaryngology, and ophthalmology. Cases beyond the scope of the up-country hospitals were transferred there. These included neurosurgical and thoracic cases and all long-term cases.

\section{Use of Helicopters}

With casualties occurring at widely separated points, often deep in the jungle, quick evacuation to hospitals has proved a major problem, still not satisfactorily solved. Until a road or suitable river was reached, casualties usually had to be hand-carried, the entire patrol taking turns and providing protection. At the roadhead, rendezvous with an ambulance was made and the casualties were taken to the nearest medical installation, which may or may not have been a surgical centre. In the latter event they were transferred after first aid and resuscitation, but the necessity of avoiding undue delay over this was stressed. A casualty evacuation flight of four HC 2 (Dragonfly) helicopters has been available for lifting wounded since the end of 1950 . From the surgeon's viewpoint this is almost the ideal method, and few things are more spectacular than a successful helicopter evacuation, the casualty, after preliminary first aid, being transported rapidly and landing on the football ground adjacent to a military hospital. However, despite numerous successful helicopter evacuations, this method has not yet proved to be the final answer to jungle warfare, and the majority of cases must still be hand-carried to roads, where they can be met by jeep or ordinary motor ambulance. The reasons for this are various.

Difficulties in maintenance of these expensive and complicated aircraft, which were based on Singapore Island, made it impracticable for them to be located strategically throughout Malaya; in fact, it often proved difficult to keep more than two aircraft fully operational at any one time. This meant delay in getting them from Singapore. Also, the helicopter must have a cleared area in which it can land safely. Because of reflected air currents it is dangerous to attempt landing close to tall trees. Although experiments have been made in "winching" patients direct to a hovering helicopter, the difficulties and risks of such a manœuvre in the jungle exclude this at present from the field of practical evacuation save in exceptional circumstances. This means that a casualty must be carried to a suitable cleared area if one exists in the locality. The preliminary selection of suitable sites for this is important if not always practicable. Should the helicopter pilot, normally guided in by Auster aircraft, regard the site as unsuitable, much time, possibly an entire day, would be wasted and the casualty would have to be taken back by traditional methods. The limitations of helicopter evacuation in dense jungle country can thus be appreciated.

On the other hand, movement by air between main towns up and down the Malay Peninsula is rapid and easy except at night, when the absence of night-landing facilities on some airfields prevents it. It has therefore been practicable to send certain types of case-for example, head wounds, spinal injuries, maxillo-facial wounds, etc.-direct to Singapore for specialized treatment not available up-country. A regular air ambulance service (Valetta) up and down the peninsula has been maintained by the R.A.F. once a week for the routine transfer of cases.

\section{Resuscitation and Transfusion}

With the relatively long time-interval between wounding and surgical treatment, the prevention of blood loss has more than ever been a matter of the utmost importance. Second only to this have been the speedy replacement of blood already lost and the prevention of infection. The last of these has proved much the easiest to achieve. As the amount of blood replacement required is determined by the amount lost, the major effort has been directed to minimizing blood loss by effective immediate first aid. A vigorous drive on first-aid training for all ranks with an operational role has paid handsome dividends. 'Most of the wounded when first seen by surgeons were reported to be in good general condition, with first-aid dressings adequately applied and fractured limbs efficiently splinted. The odd exceptions to this have merely emphasized the overall good standard and, when possible, have been made the excuse for a renewed drive on first-aid training. Initial first aid has been made primarily the responsibility. not of medical orderlies, who are seldom immediately available, but of the man's companions; and his immediate commander, irrespective of rank, is held responsible for seeing that this is done. With constant personnel changes in units, first-aid training must be frequently repeated-in fact, it should be almost continuous, a point which is apt to be forgotten. In controlling haemorrhage the emphasis has been on direct pressure correctly applied.

Blood Replacement.-Whole blood has been preferred. Initially, Group O blood was used after direct cross-typing. This was later changed to the correct group when this had been determined, if continued transfusion was necessary. 
Experience has shown that, in general, the more blood a casualty receives the better he does. This has been found to be of particular importance in determining whether or not a wound will heal by first intention after suture, in limiting or preventing minor wound infection, in accelerating bone union and skin cover, and in shortening convalescence generally. In fact, in nearly all cases in which healing has been delayed, a check on the blood has revealed a lowered haemoglobin content and blood protein. Most wounds of any severity require four to five pints (2.3 to 2.8 litres) of blood, or more if bleeding has been considerable. In addition a watch on blood haemoglobin and blood protein is necessary during the two weeks following operation in all severe cases, and any fall, which is usual, should be corrected by further transfusion. The difference between cases so treated and other cases has been remarkable.

Plasma.-Plasma was occasionally used as a preliminary to whole blood while the latter was being cross-matched and prepared. An interesting observation has been made about the storage of plasma in the Tropics. It was found at one stage that plasma (1945 and 1946 vintage) was causing a high incidence of reactions, mainly rigors and sometimes severe. In one hospital the incidence was $30 \%$. Investigations showed that the plasma had been stored for a considerable time (six months or more) at room temperature, which in Malaya is about $80^{\circ} \mathrm{F}$. $\left(26.7^{\circ} \mathrm{C}.\right)$. The plasma came to Malaya as refrigerated cargo and was kept refrigerated until issued to hospitals. When plasma which had been in continuous refrigeration was used the incidence of reactions abruptly ceased. Despite the common view that plasma can be stored at room temperature almost indefinitely, the experience in FARELF has suggested that some slow biochemical change does in fact occur in stored plasma, and that this is greatly accelerated by storage in a tropical temperature.

Plasma Substitutes.-Apart from a short trial with dextran these have been little used. The need for them has not so far arisen.

\section{Antibiotics and Chemotherapy}

In order to provide uniformity of treatment and to minimize the development of resistant strains, the following courses and dosages were adopted throughout the command :

Forward Treatment.-After securing haemostasis the wound was lightly dusted with a sulphonamide-penicillin powder, avoiding excess. This was done when possible, but was not regarded as essential. After appropriate dressing, splinting, etc., 200,000 units of penicillin was given intramuscularly. Procaine penicillin has now largely replaced crystalline for this purpose in forward areas. Injections of 200,000 units were repeated twelve-hourly (procaine) or six-hourly (crystalline) until hospital was reached Prophylactic oral sulphonamides were considered unnecessary, as carrying a risk of sulphonamide anuria in this climate.

Hospital Treatment.-For ordinary wounds penicillin was continued in the same dosage, 200,000 units six-hourly or twelvehourly, according to the type used, for five to seven days. For more serious wounds (extensive soft tissue, bone and joint, penetrating abdominal, severe multiple, etc.) or where there was evidence of established infection, a loading dose of 500,000 units of penicillin was given on admission, followed by 200,000 units twelve-hourly (procaine) or six-hourly (crystalline) for seven to ten days.

Penicillin in excess of the above dosage was rarely found necessary, though surgeons used their discretion. Supplementary sulphonamide therapy also was left to the discretion of the surgeons, but as a rule was used only when there was established infection. Sulphadimidine was preferred, and a full course was insisted upon. Streptomycin was normally given only in cases with penetrating abdominal wounds. The other antibiotics, though available, were little used. The policy was to try to prevent the development of resistant strains by keeping to penicillin in large doses and holding the other substances in reserve. This was so successful that wound infection was exceptional and resistant strains were almost unknown.
Clostridial infection was seen in only three cases-two of clostridial myositis and one of clostridial cellulitis. All cases recovered. No case of tetanus occurred.

It would appear from Malayan experience that under favourable circumstances wound infection could become almost entirely eliminated. Four factors of almost equal importance are necessary to achieve this : (a) Adequate antibiotic therapy started as soon as possible after wounding and continued for approximately one week after wound toilet. (b) Adequate wound toilet; it is essential that no debris or devitalized tissue be left. (c) Adequate blood replacement, repeated as necessary during post-operative convalescence. The aim should be to maintain blood protein and blood haemoglobin at a level as close to normal as possible. If this is done wounds will normally heal by first intention or be ready for skin cover within a few days. This requires more blood than is customarily given. (d) Complete rest of the wounded part for the next 10 days.

The first two conditions are easy to achieve. The third requires careful organization, and may be difficult if casualties occur unexpectedly in large numbers. Here plasma is a useful temporary substitute for whole blood. The fourth is normally impossible in war, but its importance wherever local conditions make it temporarily practicable (as in Malaya) is well illustrated by comparing our results with those in Korea. During a visit to Korea and Japan early in 1952 I noticed that a considerable number of casualties with wounds involving bone had developed wound infection by the time they reached hospitals in Japan from Korea, in spite of full antibiotic therapy, adequate wound toilet, and liberal blood replacement. This was in contrast to our own experience, in which established infection had been exceptional. The only difference was that their cases usually had to be moved from Korea to Japan during the first postoperative week, whereas ours remained in hospital, ensuring complete rest and enabling rather earlier delayed primary suture and, in selected cases, even primary suture to be performed. There seems to be a critical stage in the first few days after wound toilet, particularly if bone is involved, when any form of movement, however slight, may be sufficient to enable penicillin-resistant organisms to establish themselves. Any lowering of blood protein or haemoglobin also favours this.

\section{Casualty Figures for 1950-2}

The figures in Table I refer to missile wounds only, whether from enemy action or accidental, the latter including any self-inflicted wounds. They include all cases treated in military hospitals during the three-year period; and, except for a few police and civilian casualties, which were later transferred to civil hospitals, all were Service personnel.

TABLE I.-Casualty Figures

\begin{tabular}{lrr|r|r|r|r}
\hline & & 1950 & 1951 & 1952 & Total \\
\hline $\begin{array}{l}\text { Wounded admitted to hospital } \\
\text { Died in hospital }\end{array}$ &.. & 203 & $\begin{array}{r}317 \\
13\end{array}$ & $\begin{array}{r}254 \\
11\end{array}$ & $\begin{array}{r}774 \\
43\end{array}$ \\
\hline
\end{tabular}

Of the 774 casualties reaching hospital alive, 14 died soon after admission without any surgery except attempted resuscitation, and one death occurred in a civil hospital. The remainder were operated on and 28 died, giving an operative mortality of $3.7 \%$. The overall mortality was $5.5 \%$. The policy was to give every possible case the chance of surgery.

Enemy action accounted for $62.5 \%$ of the casualties admitted. The relatively high proportion of accidental wounds was mainly because battle casualties were remarkably few.

As might be expected from the type of warfare-that is, short-range ambush - the proportion of killed to wounded was high. In a series of 592 casualties from enemy action during the period under review and occurring among 
military personnel about whom full details are available, the mortality figures were:

Total casualties in series 592

Reported "killed in action" $171(28.9 \%)$

Reported "died of wounds" $32(5.4 \%$ of total casualties : $7.6 \%$ of wounded)

Of the latter, 15 (2.5\% of total casualties, $3.6 \%$ of wounded) died in hospital, the remainder en route. Thus although the mortality among casualties from enemy action was over one in three, four-fifths of these were killed in action.

Despite the relatively long delay before surgery, the overall shortage of experienced surgeons, and frequent changes due to the relatively short stay of National Service officers, the results have progressively improved with accumulated experience of local conditions (Table II).

The operative mortality in Burma in 1945 was $7.6 \%$.

TABLE II.-Operative Mortality

\begin{tabular}{c|c|c|c}
\hline Period & Cases & Total Mortality & Operative Mortality \\
\hline 1950 & 203 & $6.4 \%$ & $5.4 \%$ \\
1951 & 317 & $6.0 \%$ & $4.1 \%$ \\
1952 & 254 & $4.3 \%$ & $1.6 \%$ \\
\hline
\end{tabular}

\section{Cause of Death}

The fatal cases may be grouped as follows:

Resuscitation only, no operation

Died during operation

Failed to recover from shock

Septic complications

Post-shock renal failure

Other causes

These figures indicate where better results might have been possible. With one exception, those who were regarded as unfit for surgery died soon after admission, and their cases appear to have been hopeless. The exception was an abdominal casualty who failed to respond to resuscitation and died 10 hours later. Early operation might have saved him. The three septic complications were cerebral abscess, suppurative pericarditis, and lower-limb gangrene in which amputation had been unduly delayed. The four "other causes" were air embolism, cardiac tamponade, bronchopneumonia after craniotomy, and perforation of a thoracic stomach. All the others died directly or indirectly from the results of haemorrhage. The three deaths under anaesthesia occurred in attempts to arrest uncontrolled bleeding in chest wounds. Fifteen failed to recover from their post-operative shock, some dying soon after operation, others surviving as long as the second post-operative day. Four survived operation only to die of renal failure on the third, fifth, twelfth and twentieth day. In an endeavour to improve results, efforts were mainly directed on the group failing to recover from shock. More rapid evacuation, more individual experience in war surgery, and more liberal blood replacement may well have improved these results. Greater use of helicopters seems to be the only method of speeding evacuation.

The two factors in the present series which most influenced the mortality figures of those surviving to reach hospital were the experience of the surgeon available and the facilities for resuscitation and post-operative management. Whenever possible all serious cases should be evacuated direct to centres with full facilities, even though this may take longer. Here the helicopter is invaluable, because, once the case is airborne, distance within reason has little meaning and the extra time involved is well spent. Malayan experience has been that, provided first aid is good and resuscitation sufficient to maintain the blood pressure, time is no longer the overriding consideration, thanks to the antibiotic drugs.

\section{Wound Toilet and General Operative Technique}

Standard methods have been employed, following the experience gained during the second world war, and their use has served only to confirm their soundness. The excellence of present-day anaesthesia means that, once haemorrhage has been arrested, and with blood pressure under control and a blood drip running, time is not such a vital factor as to preclude adequate wound toilet. If this is thorough and blood replacement is adequate, complications from infection can be almost entirely eliminated, provided the patient does not have to be moved during the postoperative phase.

The only departure from standard teaching has been a return to primary suture in selected cases. This has been done because of the special circumstances of war surgery in Malaya. The avoidance of primary wound closure was one of the clearest surgical lessons of the second world war. It was therefore not without some thought that this practice was modified. However, the conditions which demanded delayed primary suture in the Western Desert and elsewhere did not apply in Malaya. Wound contamination has been minimal in the jungle: casualties go direct to military hospitals, whence there is normally no necessity to move them again until they are convalescent. Penicillin is available in large doses, and casualties never arrive in such numbers that immediate surgery is not available.

Under these conditions, and with the types of wound received in this theatre of operations, it was felt that, in selected cases, primary suture was not merely justified but might actually become the method of choice, especially when bones and joints were involved. In consequence, primary suture has been recommended, for example, in penetrating wounds of the head and chest and in wounds of the face, hand, and joints; and has been permitted at the discretion of surgeons in other suitable wounds. Necessary conditions were that there was no evidence of infection, wound toilet was adequate, and the case could be retained under the personal supervision of the surgeon for the next two weeks. In no case in which these conditions were complied with was wound infection seen. A few cases, sutured and transferred, mostly from small civil hospitals, after apparently inadequate toilet, arrived infected, and served to illustrate the danger of this method if applied to cases to be transferred. The figures are: treated by delayed primary suture, $434(51.3 \%)$; treated by primary suture, $305(36 \%)$; treated conservatively, 107 (12.6\%).

Wounds treated conservatively had skin excision only, and were practically confined to certain clean through-andthrough wounds of the chest, shoulder, and feet, or to multiple minute peppering.

It must not be taken (because of the use of primary suture in selected cases in Malaya) that there has been any change in the official teaching that, normally, primary suture has no place in military surgery. Delayed primary suture must remain the standard method of treating war wounds, except where exceptional circumstances may make deviation from this policy possible. To attempt otherwise is to court disaster.

\section{Penetrating Wounds of the Head and Spine}

The number of cases with penetrating wounds of the head and spine admitted was remarkably low despite the fact that steel helmets are not worn in Malaya. This is perhaps because most head wounds, which were nearly all inflicted at short ranges, killed outright or the casualty failed to reach hospital alive. For example, of nine men with head wounds among British troops during 1952, five were brought in dead. Only 3 cases of spinal and 15 of head wounds were admitted during the three-year period. Of the latter cases, seven were from enemy action, three were suicides, and five were accidental. Five patients were moribund on admission and died soon after; the remaining 10 had craniotomy performed, with 4 deaths. Operations were by general surgeons. Of the three patients with spinal wounds, one with quadriplegia died the same day, while two paraplegics survived to be repatriated. The average delay before operation for head wounds was 12 hours. 


\section{Penetrating Chest Wounds}

There were 57 penetrating chest wounds (excluding thoraco-abdominal) in the series, with 10 deaths. The average delay between wounding and surgery was eight hours. All cases not moribund on admission had wound toilet and closure of the chest defect with primary suture wherever possible. Subsequent management depended on the special indications and is shown in Table III.

TABLE III.-Penetrating Chest Wounds

\begin{tabular}{|c|c|c|c|c|}
\hline & Treatment & & Cases & Deaths \\
\hline $\begin{array}{l}\text { Resuscitation only } \\
\text { Wound toilet only } \\
\text { Wound toilet, thoracer } \\
\text { Wound toilet, thoraco }\end{array}$ & 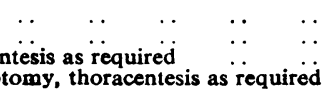 & $\begin{array}{l}\cdots \\
\cdots \\
\cdots\end{array}$ & $\begin{array}{r}2 \\
21 \\
20 \\
13\end{array}$ & $\frac{2}{7}$ \\
\hline
\end{tabular}

These chest wounds have been among the most difficulit on which to make a decision. Standard teaching, based on war experience, is that conservative treatment by wound closure, blood replacement, and repeated aspiration is the method of choice, reserving thoracotomy for cases with definite indications, and I think most experienced surgeons are in agreement with this. Nevertheless, in this series conservative treatment had a mortality rate three times that of thoracotomy. Let us examine the causes of death.

The only death after thoracotomy occurred rapidly from cardiac tamponade, 60 hours after operation. A piece of mortar shrapnel had been removed from the right pleural cavity and another piece had been felt deeply behind the heart and left as inaccessible. Of the other deaths, one followed perforation of an unsuspected intrathoracic stomach in an apparently simple through-and-through wound; two occurred soon after admission, with no surgery apart from attempted resuscitation; two occurred under anaesthesia (one during induction), both with uncontrolled bleeding; and the remainder were caused by shock within 48 hours of simple wound toilet and closure. Thoracotomy may have saved some of these, though three had severe wounds elsewhere.

In general the tendency has been for surgeons to explore the chest more often as their experience increased, the main indication being a fairly large retained fragment or evidence of severe or continued bleeding. In most cases lung lacerations were found, requiring closure, two being so extensive as to need lobectomy. There are two fallacies about chest wounds which are still apparently taught and which require exploding. One is that it is dangerous to give blood to chest cases, the other that it is equally dangerous to give morphine. Chest wounds with blood loss need adequate blood replacement just as urgently as wounds elsewhere, and, provided it is given intelligently, not too quickly, and as whole blood, this appears to carry no more risk of acute pulmonary oedema than transfusion therapy generally. Similarly, chest wounds require morphine or a similar drug in dosage sufficient to permit breathing without pain and even coughing without undue distress. It is the inability to breathe comfortably or to cough which is the main cause of failure of lung expansion and not depression of the respiratory centre by morphine, which is largely theoretical with the dosage required. When a patient's condition is precarious the ability to breathe comfortably is of great importance, and his failure to do this because of pain may well tilt the scales fatally against him.

Ultimate lung re-expansion was obtained in all cases, and usually this was rapid once surgeons appreciated the common cause of early non-expansion-that is, a plug of mucus in a bronchus. The pleural effusion on which attention tends to be focused is usually secondary to this. Only one case required decortication of the lung. Here infection of the effusion had occurred. Except for those British soldiers who were repatriated as part of the general policy, all chest cases ultimately returned to duty.
Abdominal and Thoraco-abdominal Wounds

There were 60 cases in this group, and all except 4 were operated on. The results are shown in Table IV.

TABLE IV.-Abdominal and Thoraco-abdominal Wounds

\begin{tabular}{|c|c|c|c|c|c|}
\hline & & & Cases & Deaths & Mortality \\
\hline Abdominal $\ldots \quad\left\{\begin{array}{l}\text { Not operated on } \\
\text { Operated on }\end{array}\right.$ & . & 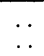 & $\begin{array}{r}2 \\
36\end{array}$ & 2 & $\begin{array}{l}100 \\
16.7\end{array}$ \\
\hline Thoraco-abdominal $\left\{\begin{array}{l}\text { Not operated on } \\
\text { Operated on }\end{array}\right.$ & .. & . & 20 & $\begin{array}{l}2 \\
5\end{array}$ & $\begin{array}{r}100 \\
25\end{array}$ \\
\hline
\end{tabular}

More surgical experience and more liberal blood replacement might well have reduced the mortality. Over half the total cases were operated on by junior surgeons with no previous experience in war surgery and only a limited experience in abdominal surgery. My personal experience has been that, provided blood replacement is liberal and surgery adequate, most abdominal wounds do well if operated on in reasonable time. So much so, that when these cases go wrong it rather suggests that there has been some error in technique or that the patient has been allowed to drift into an irreversible state of shock.

All abdominal cases were treated post-operatively with gastric suction and intravenous drip until bowel activity was well established. Of the 20 thoraco-abdominal cases operated on, 7 were approached via the chest, 12 via the abdomen, and one by both routes.

The average delay between wounding and surgery was 8.5 hours in 41 cases in which this information is available.

\section{Bone and Joint Wounds}

There were 223 patients in this group, with 9 deaths. Three of these had other severe associated wounds (two with penetrating abdominal wounds) which were the cause of death, and two were admitted moribund. Of the remaining four, two died of renal failure, one died from oligaemic shock with inadequate blood replacement, the degree of blood loss not having been appreciated, while the fourth died from fat embolism 24 hours after a wound of the upper tibia.

Excluding those dying from associated wounds, the mortality in the group was $2.7 \%$. Many of the hand and foot wounds were self-inflicted and involved metacarpals, metatarsals, or phalanges, and in addition there were a number of soft-tissue through-and-through wounds of the hands and feet which have not been included. Shooting oneself through the hand or foot was the commonest accident with weapons, and the majority seem to have been genuinely accidental. Morale was high in Malaya, with little evidence of deliberate self-infliction.

There were no special features about bone and joint wounds, which were treated by standard methods. The principles aimed at were thorough wound toilet, adequate blood replacement, adequate splinting with elevation where possible, and avoidance of movement. We were fortunate that circumstances in Malaya permitted this last principle to be followed in nearly every case, and the low incidence of infection seen was perhaps largely due to this, partly by permitting early suture but mainly by avoiding additional trauma during the next ten days or so, when bone and joint wounds seem to be peculiarly susceptible to invasion by penicillin-resistant organisms. It was found that adequately splinted wounds rarely became infected, whereas inadequately splinted wounds often did. Fortunately most of the few cases of established infection responded readily to the newer antibiotics. Experience showed that delayed primary suture is best done as soon as possible-that is, on the third or fourth day. If infection is going to occur it should be evident by then; if not, it is safe to close the wound. and the sooner exposed bone is covered the better 
If suture was delayed unduly secondary infection with penicillin-resistant organisms occurred; it was the experience with these cases which prompted the return to primary suture for selected cases. Results have justified this, and in the majority of wounds involving bone and joint uneventful first-intention healing was obtained and subsequent management was the same as that of a closed fracture.

Plaster-of-Paris was used for splinting in most cases. For upper-arm and shoulder-girdle wounds a well-padded spica was preferred. For wounds involving the knee-joint, or below, the Tobruk splint has probably proved the most effective method of immobilization: the all-important elevation can easily be obtained by this comfortable method. It is also suitable for lower-limb soft-tissue wounds, which do best when splinted in elevation. Similarly, the importance of keeping forearm and hand wounds immobilized in elevation has been repeatedly demonstrated. Provided this is done from the beginning, oedema of the hand and consequent finger stiffness are minimal. Early finger movements were insisted on.

When skin loss was extensive early skin cover was sought. Usually this could be combined with partial delayed primary suture and, when blood replacement was sufficient to keep the blood proteins up, a relatively high percentage take was achieved.

It is not possible accurately to assess final results with bone and joint wounds in Malaya because of the policy by which most severe cases in British troops were repatriated as unlikely to be fit for active operation within three months, and their ultimate disposal is unknown. However, of 128 British troops in this group 46 returned to duty, and of 48 Gurkha and African troops who were treated to finality nearly all had returned to duty; a few were still under treatment.

The average time between wounding and surgery in the bone and joint group was 12.5 hours in the 143 cases in which this information is available. The two longest delays were both 96 hours; in these two cases, a knee and a forearm wound, regular penicillin injection was not possible, and they were infected on admission. The only other cases reported infected on admission were a few which had been treated for some days elsewhere before transfer to military hospitals. With these exceptions wounds were clinically without evidence of infection on admission. Nevertheless primary suture was normally performed only on recent cases, those of eight hours or over usually having delayed primary suture, and the great majority healed by first or second intention without infection of the underlying bone. When this occurred it was typically in wounds in which skin cover had been difficult to achieve or had been delayed, or else, because of a fall in blood protein which had not been corrected, the wound broke down secondarily. These cases, after skin cover was obtained and any small sequestra were removed, practically all healed with suitable antibotic treatment. Very few still had low-grade infection when repatriated. No case required amputation because of chronic infection. Major amputation had to be resorted to in five cases only, all because of major-vessel injury and a nonviable limb.

These results are significant. They show that with the use of penicillin in adequate dosage wound infection can be long deferred and time as such ceases to be all-important. It is haemorrhage and shock which are most likely to kill these patients, and sufficient time should be taken to ensure adequate splinting and blood replacement. Good first aid is of the greatest importance.

\section{Maxillo-facial Wounds}

A senior dental specialist working with a senior surgeon was located at the Singapore Military Hospital, to which all maxillo-facial cases were transferred, usually by air and usually after preliminary toilet up-country.

In the 18 cases in this group the mandible was involved in 11 , the maxilla in 7 , and other bones in 2 . Two men died from severe multiple associated wounds. Six British cases were repatriated; the others were treated to finality and returned to duty with satisfactory functional and cosmetic results. Treatment was on standard lines. The average delay between wounding and first surgical operation was 17.2 hours.

\section{Soft-tissue Wounds}

Of the 555 soft-tissue wounds reported, approximately two-thirds were major wounds. Each distinct major wound has been counted, but with minor wounds each casualty has been counted as one wound only, because the majority (over $80 \%$ ) had received multiple grenade or buckshot wounds, involving soft-tissue penetration of many small fragments, to varying depth. Some of these required considerable surgical toilet, others were treated entirely conservatively. In general, small fragments were left. Minor wounds that were associated with major wounds have not been counted. Major soft-tissue wounds have been arbitrarily defined as those causing considerable muscle or other soft-tissue damage and demanding major wound toilet, also through-and-through wounds. Most of the major wounds in the group were treated by excision and delayed primary suture, which is still regarded as the only safe method where there is any degree of muscle damage.

In some sites, particularly the shoulder, small clean through-and-through wounds, such as those resulting from carbine bullets, were sometimes treated conservativelythat is, by skin excision only. No case of wound infection occurred after this, and recovery of function was usually much more rapid and complete than after extensive full excision. The skin wounds were left open for drainage. Most of these wounds occurred through a thin cotton shirt only. Shoulder wounds should be treated in abduction: some cases in which this was omitted had considerable shoulder-stiffness with limited abduction. Although this method is potentially dangerous and cases need careful watching, it was felt that, with the favourable circumstances in Malaya, the advantages outweighed the disadvantages for many shoulder wounds, and most cases returned early to duty with a full range of shoulder movements. For through-and-through wounds elsewhere, opening up and excision of the tract was the method normally adopted: conservative treatment is specially dangerous with throughand-through leg wounds.

Clean superficial wounds were usually excised and sewn up as in civil practice, generally with first-intention healing. Nevertheless, experience with primary suture in this theatre has done nothing to alter the standard teaching that it has little place in military surgery except where special local conditions approximating to ordinary civilian practice occur.

Soft-tissue wounds included 42 major nerve injuries. All British casualties were repatriated for treatment as longterm cases. Asian cases were treated locally.

Very few major vascular injuries occurred. Only eight major arterial wounds were recorded, of which five required amputation (upper limb one, lower limb four). One patient died in a civil hospital.

\section{General Remarks}

Although the number of wounds in this series was comparatively small-in fact, too small for most individual surgeons to attain experience and skill comparable to that developed by surgeons during the late world war-this has in part been compensated for by devoting more time to individual cases and by being able to follow them through personally. However, although experience in Malaya has confirmed the soundness of the principles of wound surgery developed during the second world war, there have been certain developments since which are of importance. These are : 
(1) Under present conditions in Malaya, with penicillin available in sufficient dosage and supplemented if necessary by the newer antibiotics, wound infection can be so greatly retarded as to make the time element, from this aspect, no longer important. Under favourable conditions serious wound infection should be almost eliminated.

(2) Some wounds are of course lethal, killing either immediately or very soon after wounding. There is little that can be done about these except to try to reduce their incidence by good battle-training and possibly by some form of protection such as the laminated nylon vest. The great majority of deaths from wourds, not of themselves necessarily lethal, occur directly or indirectly from haemorrhage. This must be regarded as a preventable condition, and efforts to reduce mortality from missile wounds can be directed with much profit along these lines. The three main life-saving procedures in such cases are adequate first aid to limit bleeding from accessible sites; quick adequate blood replacement for cases with oligaemic shock, actual or imminent; and speedy evacuation to a surgical centre of any case with inaccessible bleeding. There is nothing new about these fundamental principles; nevertheless, many of the deaths in the series under review were due either to failure or to inability to apply them. They cannot be restated too often.

(3) Helicopter evacuation has come to stay. It will not always be available, because we are unlikely always to have the local air superiority essential for the operation of these vulnerable aircraft. When they can be used, however, they are life-saving and should be the normal method by which penetrating wounds of the head, spine, chest, and abdomen, maxillo-facial wounds, and those involving the femur or major vessels are evacuated. Apart from the time saved and the minimization of shock while in transit, they have the tremendous advantage that, once airborne, they can cover considerable distances quickly and so enable serious cases to be operated on well in the rear, where adequate surgical and nursing facilities can be provided and the need for subsequent speedy evacuation is less urgent.

Any report on war surgery in Malaya would be incomplete without a tribute to all ranks of the Army Medical Services responsible for the management of these cases. Despite constant shortages of staff which necessitated long hours of work, their efforts have been tireless, and the fact that the results obtained are the best in the history of the British Army is entirely due to the high quality of their team-work. In particular we have been indebted to the junior surgeons and anaesthetists, without whom it would have been impossible to carry on.

\section{Summary}

Missile wounds in 774 casualties sustained during a threeyear period in Malaya are reviewed. The mortality among cases alive on admission to hospital was $5.5 \%$ and among cases fit for surgery $3.7 \%$.

Management of wounds followed the principles developed during the second world war and confirmed their soundness.

The causes of death are discussed and suggestions made for reducing them.

I am indebted to Brigadier C. W. Greenway, Director of Medical Services, Far East Land Forces, for permission to send these notes for publication.

\section{SPEECH AFTER REMOVAL OF UPPER END OF OESOPHAGUS AND THE LARYNX}

BY

A. C. DORNHORST, M.D., M.R.C.P.

Reader in Medicine, St. Thomas's Hospital Medical School, London

\section{AND}

V. E. NEGUS, D.Sc., M.S., F.R.C.S. Consulting Surgeon to King's College Hospital, London

The disease generally known as post-cricoid carcinoma usually arises on the upper surface of the cricopharyngeal fold at the mouth of the oesophagus. The incidence is, unfortunately, of sufficient frequency to present a serious problem in treatment. The growth tends to infiltrate the back of the larynx and is usually far advanced before compelling the patient to seek advice; its progress is such as to inflict great suffer-

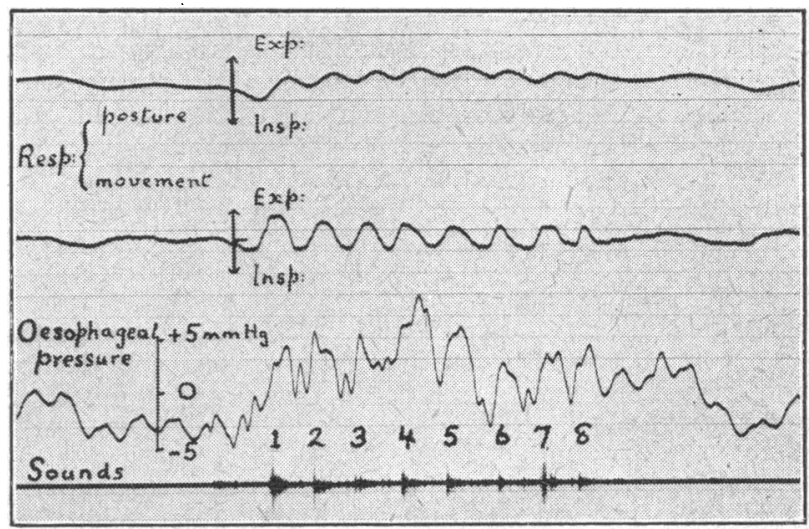

FIG. 1.-Recording of respiratory movements, oesophageal pressure, and sounds while patient counts up to eight. Each sound occurs as the oesophageal pressure rises during a sharp expiratory movement.

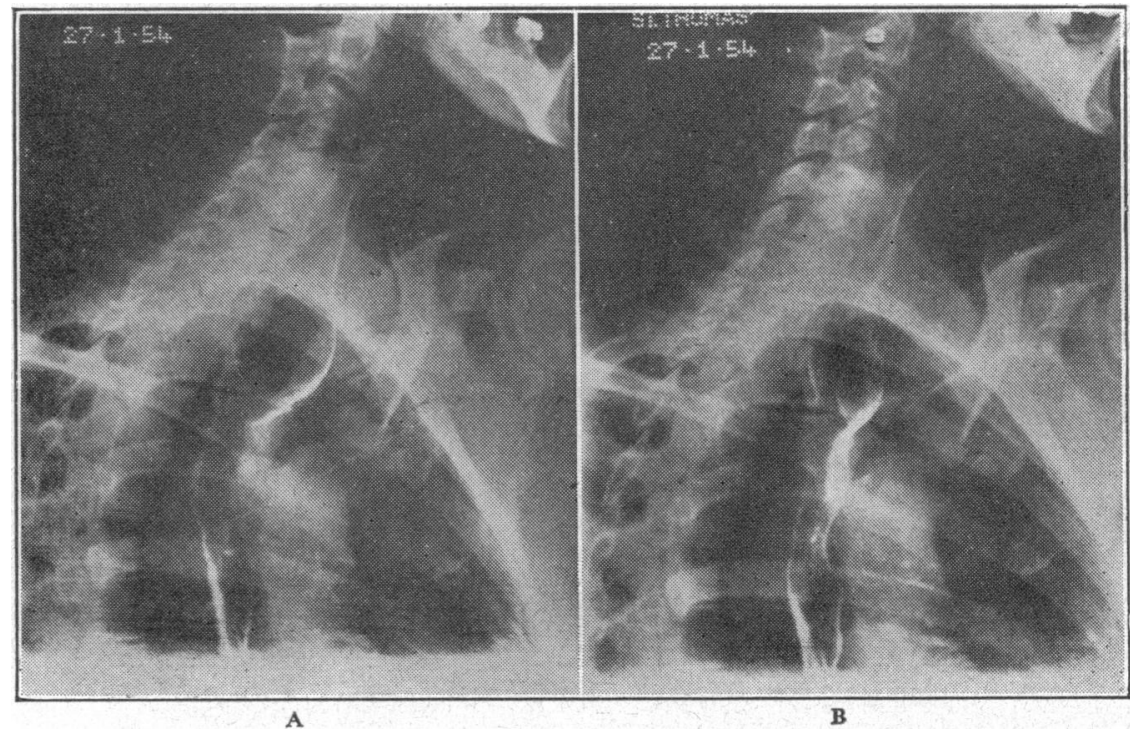

FIG. 2.-Upper part of oesophagus and the reconstituted pharynx, showing the falling together of the anterior and posterior walls at about the upper limit of the graft. A, during speech. B, after speaking. The junction of skin tube and oesophagus is widely open during speech; the skin tube is distended by escaping air. 